\title{
Article \\ A Smart Heterogeneous Catalyst for Efficient, Chemo- and Stereoselective Hydrogenation of 3-Hexyn-1-ol
}

\author{
Stefano Paganelli ${ }^{1, *}$, Alessio Angi ${ }^{1}$, Nicolò Pajer ${ }^{1}$ and Oreste Piccolo ${ }^{2, *}$ \\ 1 Dipartimento di Scienze Molecolari e Nanosistemi, Università Ca' Foscari Venezia, Via Torino 155, \\ 30172 Venezia Mestre (VE), Italy; angi.alessio.93@gmail.com (A.A.); nicolo.pajer@unive.it (N.P.) \\ 2 Studio di Consulenza Scientifica (SCSOP), Via Bornò 5, 23896 Sirtori (LC), Italy \\ * Correspondence: spag@unive.it (S.P.); contact@scsop.it (O.P.); Tel.: +39-0412348592 (S.P.); \\ $+39-3356828222$ (O.P.)
}

check for

updates

Citation: Paganelli, S.; Angi, A.; Pajer,

N.; Piccolo, O. A Smart Heterogeneous Catalyst for Efficient, Chemo- and Stereoselective Hydrogenation of 3-Hexyn-1-ol. Catalysts 2021, 11, 14. https://dx.doi.org/10.3390/ catal11010014

Received: 7 November 2020 Accepted: 22 December 2020 Published: 25 December 2020

Publisher's Note: MDPI stays neutral with regard to jurisdictional claims in published maps and institutional affiliations.

Copyright: () 2020 by the authors. Licensee MDPI, Basel, Switzerland. This article is an open access article distributed under the terms and conditions of the Creative Commons Attribution (CC BY) license (https: / / creativecommons.org/ licenses/by/4.0/).

\begin{abstract}
We examine the easy preparation of mono- and bi-metallic heterogeneous catalysts with low Pd and $\mathrm{Cu}$ contents on alumina and provide a detailed study of many reaction parameters in the catalyzed selective semihydrogenation of 3-hexyn-1-ol to (Z)-3-hexen-1-ol, a very important fragrance with an herbaceous note. In particular, two different protocols of Pd catalyst preparation, substrate/catalyst molar ratio, the effect of time and temperature, introduction of some additives to the reaction mixture, and the nature of the solvent were investigated. These factors are not independent variables. The results show that it is possible to control the reaction outcome to obtain the target $(Z)$-alkenol using different experimental conditions. The best result, as an appropriate compromise between conversion and selectivity, may be obtained by working with a very high substrate/catalyst molar ratio (>6000/1), with one type of Pd catalyst, in a short time (about $150 \mathrm{~min}$ ) at $60{ }^{\circ} \mathrm{C}$.
\end{abstract}

Keywords: heterogeneous catalyst; selective hydrogenation; alkyne; (Z)-alkene; fragrance

\section{Introduction}

The selective hydrogenation of unsaturated substrates is a powerful tool for the preparation of both bulk and fine chemicals [1-3]. The design of an efficient catalyst to obtain a high chemo- and/or stereo-selectivity without loss of catalytic activity is often still a challenge. Homogeneous catalysts are more selective than heterogeneous ones due to the steric and electronic effects of the ligands, but heterogeneous catalysts are preferable from an industrial point of view as they can be easily separated and reused. For this reason, metals supported on charcoal, zeolites, or oxides, such as $\mathrm{SiO}_{2}$ or $\mathrm{Al}_{2} \mathrm{O}_{3}$, are largely employed and the selectivity strongly depends on the adsorption strength and configuration of both reactants and intermediates on the surface of the catalyst, which in turn is determined by the electronic and geometric structures of the active sites [4,5]. As a result, the preparation process of the catalyst plays a fundamental role. An interesting aspect of selectivity is the semihydrogenation of alkynes to alkenes with strong relevance for industrial applications [6-26]. Chemoselectivity is important for internal alkynes, but it is not the only parameter to consider: another crucial aspect for producing $(Z)$ or $(E)$ isomers is stereoselectivity. This underlines that a subsequent isomerization from $(Z)$ to $(E)$ isomers may occur in the reaction mixture being catalyzed by the same heterogeneous metallic species. In this work, we focused on the selective reduction of 3-hexyn-1-ol (I) to produce mostly the corresponding (Z)-3-hexen-1-ol [(Z)-(II)] [27-29] (Scheme 1). 


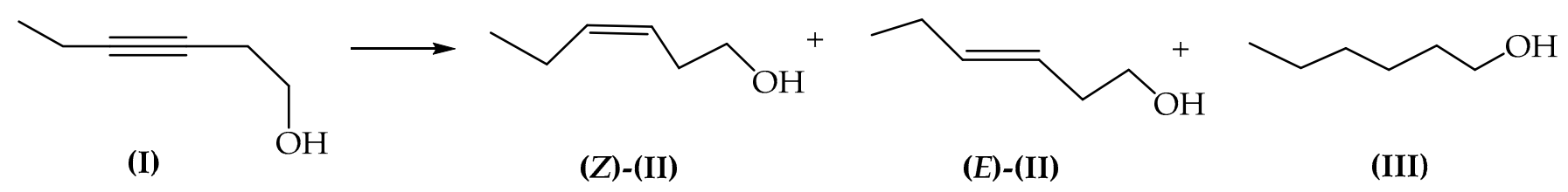

Scheme 1. Hydrogenation of 3-hexyn-1-ol (I).

Compound (Z)-(II) is found in various natural essential oils and aroma-active volatiles, and it is currently used in many perfumes because of its powerful, fresh, green, grassy, and herbaceous notes $[27,30,31]$. With this aim, we prepared two heterogeneous $0.25 \%$ $\mathrm{Pd} / \mathrm{Al}_{2} \mathrm{O}_{3}$ catalysts (Cat 1 and Cat $1^{*}$ ), following a general smart methodology developed in our laboratory to prepare low metal content heterogeneous catalysts on alumina $[32,33]$. The preparation of these two catalysts differs only in the addition of alumina: in the case of Cat 1, it was introduced as a solid into the reaction mixture containing the colloidal reduced metal in cyclopentyl methyl ether (CPME); for Cat $1^{*}$, the reaction mixture containing the colloidal reduced metal was added to a suspension of alumina in CPME. Some publications claim there is an advantage to using bimetallic catalysts, in particular catalysts containing $\mathrm{Pd}$ and $\mathrm{Cu}$, for the semi-hydrogenation of alkynes $(20,21,23,26)$. As a result, we decided to explore for the first time the synthesis of a bimetallic catalyst $(0.156 \% \mathrm{Cu}, 0.075 \% \mathrm{Pd}) / \mathrm{Al}_{2} \mathrm{O}_{3}$ (Cat 2) using a one-pot protocol, where regents were placed all together in the reactor. Here, we present the results obtained by investigating the influence of numerous reaction parameters, such as catalyst preparation protocol, amount of catalyst, temperature, reaction time, presence of some additives, and nature of the solvent in the semihydrogenation of $\mathbf{I}$ in the effort to identify suitable conditions to maximize both substrate I conversion and selectivity to (Z)-(II).

\section{Results and Discussion}

The preparation of these $0.25 \% \mathrm{Pd} / \mathrm{Al}_{2} \mathrm{O}_{3}$ catalysts, as described in the experimental section, is simple, requiring no special equipment or energy-intensive reactions. It is characterized by the absence or limited amount of water in the reaction mixture, unlike the procedures commonly used to prepare supported metal catalysts $[5,28]$. Our protocol is affected by the type of alumina used as support [33] and has a good reproducibility. The catalysts, if stored under controlled conditions to avoid unwanted contact with humidity and air, maintain a good stability over time. In the laboratory, we have always adopted a two-pot protocol to prepare the Pd catalysts; however, here, we decided to explore a different order of the addition of alumina with the aim to improve the homogeneity of the catalyst and to reduce possible variability effects. A preliminary investigation of the structure of two catalyst samples, prepared with these two procedures, was performed by SEM analysis (Figures S1-S5). In the Cat $1^{*}$ sample, the average metal particle size was significantly smaller $(<<100 \mathrm{~nm}$ ) compared with those of Cat 1 (where bigger metal particles up to $200 \mathrm{~nm}$ were present), and a better distribution occurred. As preliminary work, we also explored the outcome of the simpler one-pot procedure, inspired by the $\mathrm{Rh} / \mathrm{Al}_{2} \mathrm{O}_{3}$ industrial protocol [34], but we only have a limited number of results for the Pd catalyst at present, which calls for a more detailed study, but this did not affect the present work. The bimetallic catalyst $(0.156 \% \mathrm{Cu}, 0.075 \% \mathrm{Pd}) / \mathrm{Al}_{2} \mathrm{O}_{3}$ was prepared using the one-pot procedure, requiring more drastic conditions to achieve the reduction of both metals.

The results obtained with our catalysts and with a commercial one specifically claimed for this application [28] (Figure 1, Figure 2, Figures 3-6; Tables S1, S2, S3, S4, S5, S6) are reported and discussed. The amount of all compounds in the reaction mixture, denoted as the area percentage, was determined at different reaction times by GC analysis using pure compounds as references. Stereoselectivity was calculated as: $\{(\mathrm{Z})-(\mathrm{II}) /[(\mathrm{Z})-(\mathrm{II})+(\mathrm{E})-(\mathrm{II})]\}$. 

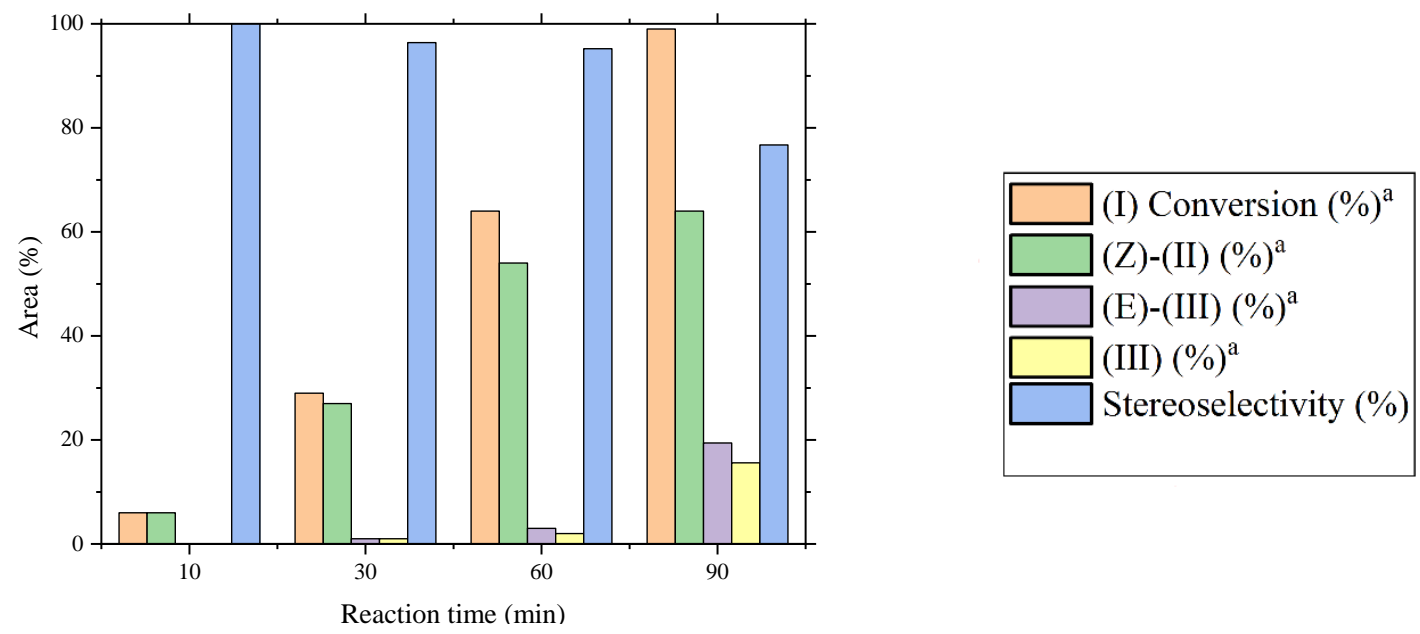

Figure 1. Hydrogenation of (I) catalyzed by Cat 1. Preliminary investigation. Substrate $(\mathbf{I})=138.4 \mathrm{mg}(1.41 \mathrm{mmol}) ;(\mathbf{I}) / \mathrm{Pd}$ $(\mathrm{mol})=500 ; \mathrm{pH}_{2}=0.1 \mathrm{MPa}$; Solvent $=\mathrm{i}$-propanol $(10 \mathrm{~mL}) ; \mathrm{T}=25^{\circ} \mathrm{C}$. ${ }^{\mathrm{a}}$ Area percentage determined by GC analysis.

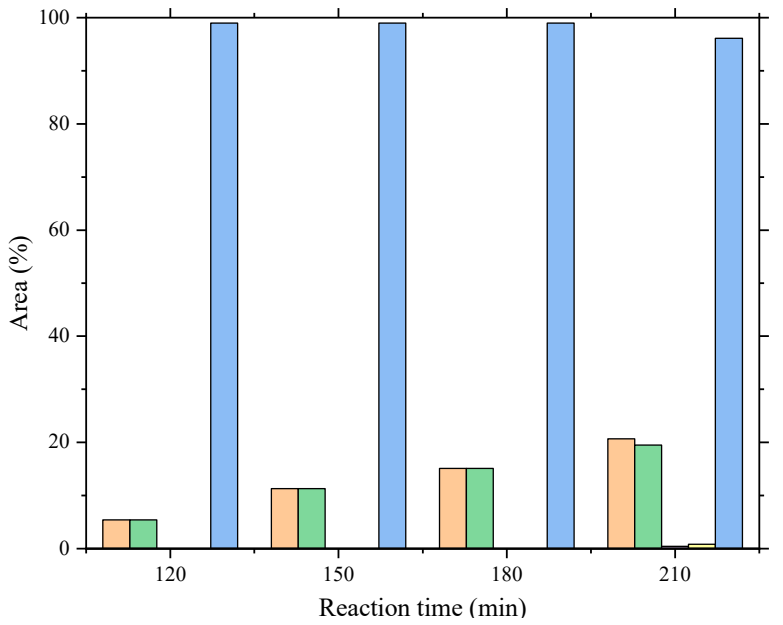

\begin{tabular}{|c|c|}
\hline & (I) Conversion $(\%)^{\mathrm{a}}$ \\
\hline & ](Z)-(II) $(\%)^{\mathrm{a}}$ \\
\hline & ](E)-(III) $(\%)^{\mathrm{a}}$ \\
\hline & ]$(\mathrm{III})(\%)^{\mathrm{a}}$ \\
\hline & Stereoselectivity (\%) \\
\hline
\end{tabular}

Figure 2. Hydrogenation of (I) catalyzed by a commercial catalyst. [BASF (catalyst code 543136) $0.6 \%$ Pd/C]. Substrate $(\mathrm{I})=138.4 \mathrm{mg}(1.41 \mathrm{mmol}) ;(\mathrm{I}) / \mathrm{Pd}(\mathrm{mol})=500 ; \mathrm{pH}_{2}=0.1 \mathrm{MPa}$; Solvent = i-propanol $(10 \mathrm{~mL}) ; \mathrm{T}=25^{\circ} \mathrm{C}$. Area percentage deter-mined by GC analysis.

A first set of experiments (Figure 1; Table S1) was carried out using Cat 1 in i-propanol at $0.1 \mathrm{MPa}$ of $\mathrm{H}_{2}$. This catalyst showed very high activity, even at room temperature, and very short reaction times using a substrate $/ \mathrm{Pd}$ molar ratio $=500 / 1$. Given the same experimental conditions, its activity is surprisingly much higher than that of a commercial benchmark catalyst [28] (Figure 2; Table S2). Unfortunately, at total conversion after $90 \mathrm{~min}$, only $64 \%$ of (Z)-(II) formed, as $19.4 \%$ of (E)-(II) and $19.6 \%$ of hexanol (III) were also produced (Figure 1; Table S1, Run $1\{90\}$ ).

To better control of the reaction, we explored the use of some additives, as $t$ dopants may modulate the activity and selectivity of heterogeneous catalysts, too. In particular, the Pd Lindlar catalyst, generally used in semihydrogenation of alkynes, is characterized by the presence of lead acetate or lead oxide and/or quinoline as poisons [6,21]. In previous works that we carried out on two-phase aqueous organic solvent reactions, we found that ammonium acetate, a very hygroscopic reagent, was an efficient additive to modulate the activity of a catalyst. To limit the presence of water in the reaction mixture, we decided to prepare ammonium acetate in situ. So, $\mathrm{NH}_{4} \mathrm{Cl}$ and $\mathrm{CH}_{3} \mathrm{COONa} \cdot 3 \mathrm{H}_{2} \mathrm{O}$, both in equimolar amount with the substrate, were added to the reaction mixture. After $3 \mathrm{~h}$ at room temperature and $0.1 \mathrm{MPa}$ of $\mathrm{H}_{2}$, using a substrate/Pd molar ratio $500 / 1$, the conversion was $>89 \%$, the stereoselectivity to (Z)-(II) was very high (up to $97 \%$ ) and III 
was not obtained at all or was produced in a very limited amount (Figure 3A; Table S3, Run $1\{180,210\})$.
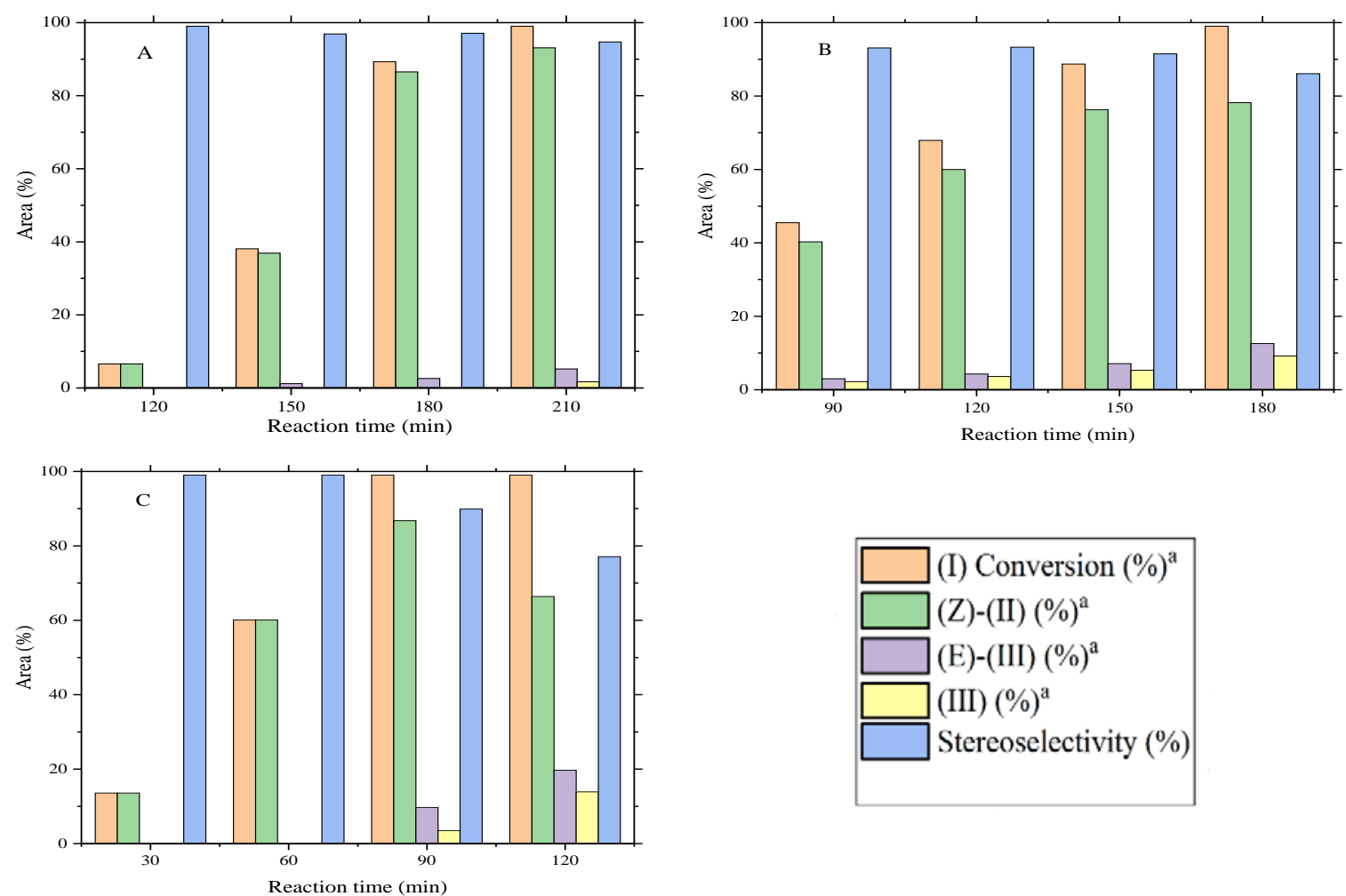

Figure 3. Hydrogenation of $\mathbf{I}$ catalyzed by Cat 1, in the presence of additives. Substrate $\mathbf{I}=138.4 \mathrm{mg}(1.41 \mathrm{mmol})$; $(\mathrm{I}) / \mathrm{Pd}(\mathrm{mol})=500 ; \mathrm{pH}_{2}=0.1 \mathrm{MPa}$; Solvent = i-propanol $(10 \mathrm{~mL}) ; \mathrm{T}=25{ }^{\circ} \mathrm{C}$. (A): $75 \mathrm{mg}$ of $\mathrm{NH}_{4} \mathrm{Cl}$ and $192 \mathrm{mg}$ of $\mathrm{CH}_{3} \mathrm{COONa} \cdot 3 \mathrm{H}_{2} \mathrm{O}$; (B): $75 \mathrm{mg}$ of $\mathrm{NH}_{4} \mathrm{Cl} ;(\mathbf{C}): 192 \mathrm{mg}$ of $\mathrm{CH}_{3} \mathrm{COONa} \cdot 3 \mathrm{H}_{2} \mathrm{O}$. a Area percentage determined by $\mathrm{GC}$ analysis.

This result showed that by reducing the activity of Cat 1 with this cheap and benign dopant mixture, it was possible to improve the fine tuning of chemo- and stereoselectivity. When the same reaction was carried out in the presence of the sole $\mathrm{NH}_{4} \mathrm{Cl}$ or sole $\mathrm{CH}_{3} \mathrm{COONa} \cdot 3 \mathrm{H}_{2} \mathrm{O}$, the activity of the catalyst was enhanced, but both chemo- and stereoselectivity were lowered, especially with the former additive (Figure 3B; Table S3 ls, Run 2). Interestingly, by working with the latter dopant, it was possible to obtain the (Z)-isomer in quantitative yield by limiting the conversion to $60 \%$. Additionally, in this case, an enhancement of the reaction time resulted in complete conversion, although it was achieved at the expense of selectivity (Figure 3C; Table S3, Run 3). By comparing these results with those obtained using the same reaction conditions in the absence of any additive, we assert that sodium acetate might exert a positive effect in terms of selectivity to (Z)-(II) while maintaining a comparable activity.

To verify the possible influence of the solvent in this reaction, we performed some comparative hydrogenation experiments in CPME, the solvent used for the preparation of the catalyst, (Figure 4A; Table S4) and in i-propanol (Figure 4B; Table S4). The reaction in $\mathrm{CPME}$ was carried out at $25^{\circ} \mathrm{C}$, while that of $\mathrm{i}-\mathrm{PrOH}$ was carried out at $60^{\circ} \mathrm{C}$. 

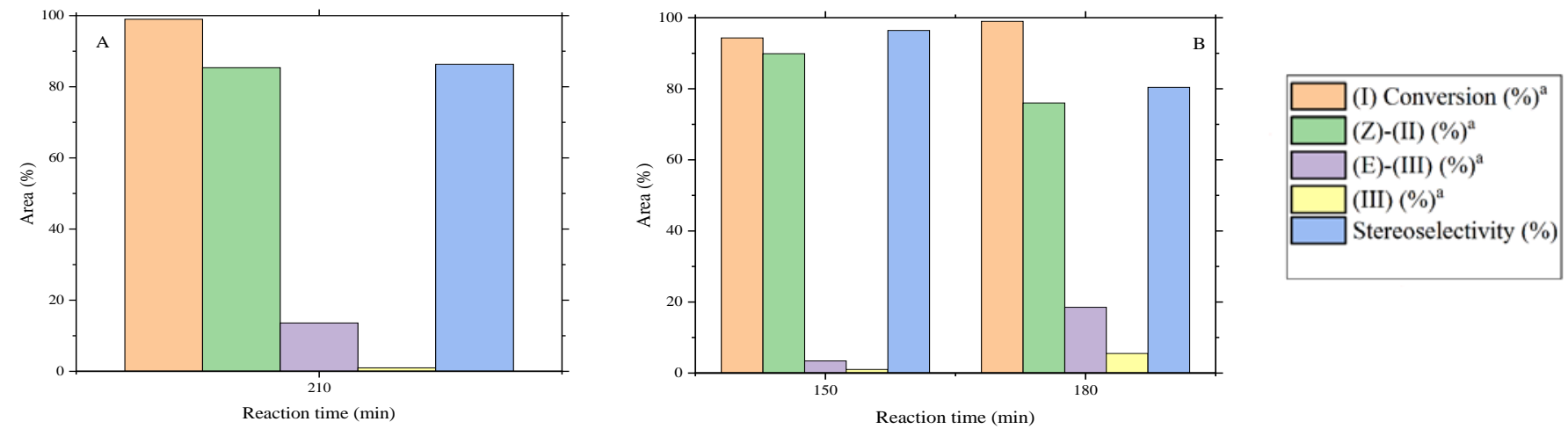

Figure 4. Hydrogenation of I catalyzed by Cat 1 in CPME (A) and in i-propanol (B). Substrate I = $138.4 \mathrm{mg}(1.41 \mathrm{mmol})$; $(\mathrm{I}) / \mathrm{Pd}(\mathrm{mol})=2000 ; \mathrm{pH}_{2}=0.1 \mathrm{MPa}$; Solvent $=10 \mathrm{~mL}$. ${ }^{\text {A }}$ Area percentage determined by GC analysis.

Even if, surprisingly, the activity of the catalyst was very high in CPME with a good selectivity, it was not possible to remove it completely from (Z)-(II) by distillation. For this reason, i-propanol remains the solvent of choice for this application. However, CPME might be useful for the hydrogenation of other substrates that are characterized by a higher boiling point and it may be possible to use the catalyst without drying it.

Through the use of Cat $1^{*}$, it was possible to work with a much higher substrate/Pd molar ratio $\left(6000 / 1-10,000 / 1 ; \mathrm{TOF}=2260-2400 \mathrm{~h}^{-1}\right)$ and to obtain promising results in terms of both conversion and selectivity to the target compound (Z)-(II) (Figure 5B-D,G; Table S5, Runs 2,3,6). We think that the higher activity may be related to the smaller particle sizes of the metal and to the better homogeneity of Cat $1^{*}$ as shown by SEM analysis. If we compare Figure 5B,C corresponding to Table S5 (Runs 2 and 3 at $120 \mathrm{~min}$, respectively), it is possible to deduce that the procedure is reproducible $( \pm 5 \%)$. Furthermore, the catalyst of Figure 5D (Table S5, Run 3) was recycled twice after a pre-treatment with $0.1 \mathrm{MPa}$ of hydrogen for $2 \mathrm{~h}$ at $60^{\circ} \mathrm{C}$ (Figure 5E,F; Table S5, Runs 4 and 5). A lower level of activity was observed when stopping the reaction at the same time, but, in our opinion, it was likely due to an unwanted small loss of catalyst during the catalyst separation and reuse rather than a metal leaching in the organic phase; to confirm the absence of traces of leached metal, after the separation of Cat $1^{*}$, a sample of 1-undecene was added to the organic phase and the mixture was treated at $80^{\circ} \mathrm{C}$ under $5 \mathrm{MPa}$ of $\mathrm{H}_{2}$ for $6 \mathrm{~h}$, but undecane was not detected. 

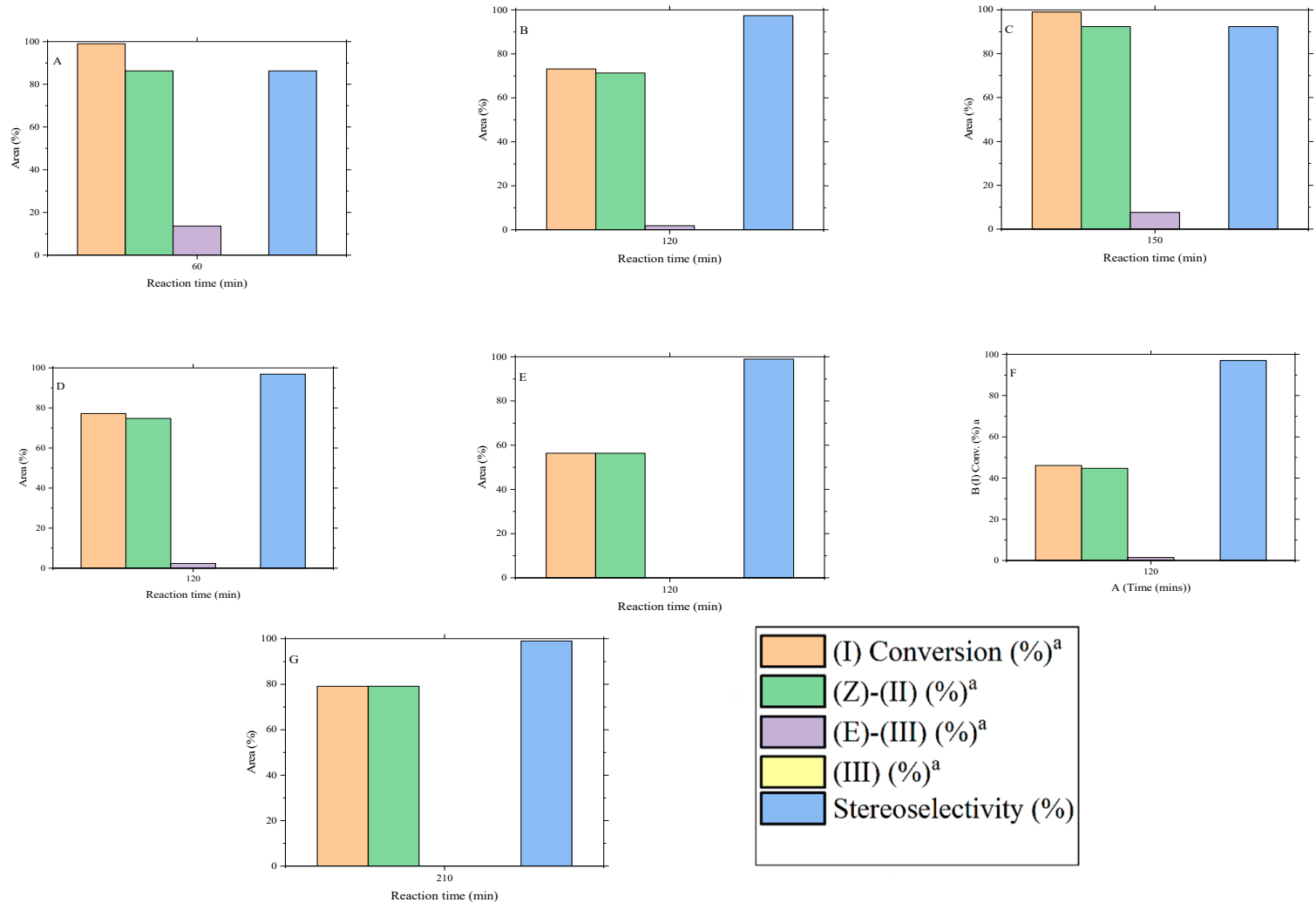

Figure 5. Hydrogenation of (I) catalyzed by Cat $1^{*}$. Substrate $\mathbf{I}=332.1 \mathrm{mg}(3.38 \mathrm{mmol}) ; \mathrm{pH}_{2}=0.1 \mathrm{MPa}$; Solvent $=\mathrm{i}$-propanol $(10 \mathrm{~mL}) ; \mathrm{T}=60{ }^{\circ} \mathrm{C}$. (A): (I) $/ \mathrm{Pd}(\mathrm{mol})=2000 ;(\mathbf{B}),(\mathbf{C}),(\mathbf{D}):(\mathrm{I}) / \mathrm{Pd}(\mathrm{mol})=6000 ;(\mathrm{E}):$ Recycling the catalyst used in (D); (F): Recycling the catalyst used in $(\mathbf{E}) ;(\mathbf{G}):(\mathbf{I}) / \mathrm{Pd}(\mathrm{mol})=10,000$. ${ }^{a}$ Area percentage determined by GC analysis.

Finally, we explored the synthesis of a bimetallic catalyst, $(0.156 \% \mathrm{Cu}, 0.075 \% \mathrm{Pd}) /$ $\mathrm{Al}_{2} \mathrm{O}_{3}$, to reduce the amount of precious metal, on the basis of numerous literature reports $[13,20,21,23]$, which suggested a positive effect when using a catalyst containing both $\mathrm{Pd}$ and $\mathrm{Cu}$. As better described in the experimental section, the catalyst was prepared using the simplified one-pot procedure, and Cat 2 was used in the hydrogenation of $\mathbf{I}$. The preliminary data described in Figure 6 and Table S6 point out, as expected, a much lower catalytic activity with respect to that of Cat 1 (Figure 1; Table S1), but a slightly improved selectivity that requires further studies to be confirmed. Unfortunately, it was not possible to recycle this catalyst because its activity was lost completely after the work-up and any attempt to regenerate it through a pre-treatment with hydrogen failed.
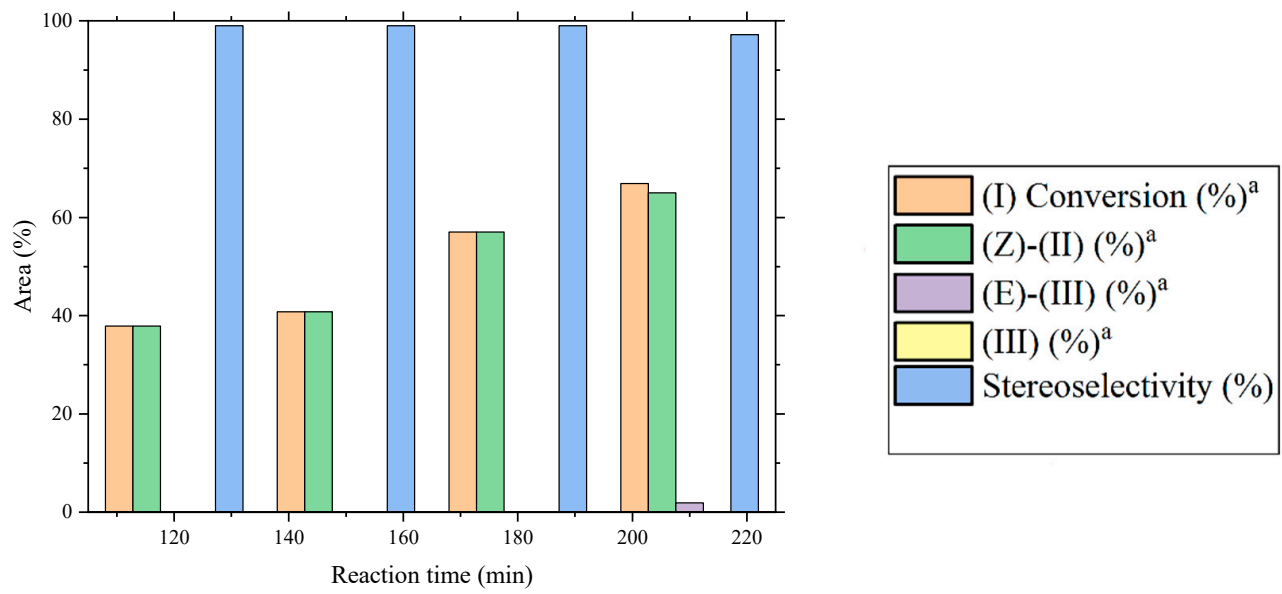

Figure 6. Hydrogenation of $(\mathbf{I})$ catalyzed by Cat 2. Substrate $\mathbf{I}=172.7 \mathrm{mg}(1.76 \mathrm{mmol}) ;(\mathbf{I}) / \mathrm{Cu}, \mathrm{Pd}(\mathrm{mol})=500 ; \mathrm{pH}=0.1 \mathrm{MPa}$; Solvent $=$ i-propanol $(10 \mathrm{~mL}) ; \mathrm{T}=40^{\circ} \mathrm{C}$. ${ }^{\mathrm{a}}$ Area percentage determined by GC analysis. 


\section{Materials and Methods}

\subsection{General}

3-hexyn-1-ol, cyclopentyl methyl ether (CPME), trioctyl amine (TOA), ammonium chloride, sodium acetate trihydrate, palladium chloride, cuprous chloride, and isopropanol (i-PrOH) were Aldrich products (St. Louis, $\mathrm{MO}$, USA). $\gamma-\mathrm{Al}_{2} \mathrm{O}_{3}$ was a generous gift of Chimet S.P.A (Badia al Pino (AR), Italy). Catalyst $0.6 \% \mathrm{Pd} / \mathrm{C}$ (543136) was a generous gift of BASF. (Z)- and (E)-3-hexen-1-ol, as reference compounds, were a generous gift of Novachem Aromatici S.r.l. (Gallarate (VA), Italy). The amounts of $\mathrm{Pd}$ and $\mathrm{Cu}$ contained in these catalysts were determined using a Perkin Elmer Analyst 100 spectrometer equipped with a single-element hollow cathode lamp. SEM analyses were carried out using a TM3000 Hitachi instrument coupled with a Swift ED 3000 (Oxford Instruments, Abingdon, UK). GC analyses were carried out on an Agilent 6850A gas chromatograph (FFAP column $30 \mathrm{~m} \times 0.25 \mathrm{~mm} \times 0.25 \mu \mathrm{m}$; low $0.7 \mathrm{~mL} / \mathrm{min}$, pressure $0.689 \mathrm{bar} ; 10{ }^{\circ} \mathrm{C} \times 5 \mathrm{~min}$, followed by a heating rate of $0.5^{\circ} \mathrm{C} / \mathrm{min}$ up to $240{ }^{\circ} \mathrm{C}$ and further $19 \mathrm{~min}$; retention time: (III) $7.10 \mathrm{~min},(E)-(\mathbf{I I}) 7.50 \mathrm{~min},(\mathrm{Z})$-(II) $8.10 \mathrm{~min}$, (I) $13.10 \mathrm{~min}$. GC-MS analyses were performed using an Agilent Technologies 7820A GC System coupled with quadrupole mass spectrometer Agilent Technologies 5977B MSD (HP-5MS column $30 \mathrm{~m} \times 0.25 \mathrm{~mm} \times 0.25 \mu \mathrm{m}$ ). In the Figures (tables in Supplementary Materials), the amount of compounds in the final mixture is reported as the area percentage. Conversion is based on the amount of starting material observed in the final mixture. The area percentage corresponds to the real amount of the compounds in the mixture, using pure standards. Stereoselectivity was calculated as: (Z)-(II) $/[(\mathrm{Z})-(\mathrm{II})+(\mathrm{E})-(\mathrm{II})]$.

\subsection{Preparation of Cat 1 and Cat $1^{*}$}

In a Schlenk tube, $25 \mathrm{mg}(0.15 \mathrm{mmol})$ of $\mathrm{PdCl}_{2}$ and $0.22 \mathrm{~mL}(0.50 \mathrm{mmol})$ of TOA were stirred under nitrogen in $5 \mathrm{~mL}$ of CPME. The Schlenk tube was transferred into a $150 \mathrm{~mL}$ stainless steel autoclave, pressurized with $0.1 \mathrm{MPa}$ of $\mathrm{H}_{2}$ and stirred for $24 \mathrm{~h}$ at $25^{\circ} \mathrm{C}$. Then, the residual gas was released and the reaction mixture was transferred into a $50 \mathrm{~mL}$ double-neck jacket round-bottom flask. CPME $(10 \mathrm{~mL})$ and $\gamma-\mathrm{Al}_{2} \mathrm{O}_{3}(5 \mathrm{~g})$ were added and the stirred mixture was maintained under a hydrogen atmosphere at room temperature. After $24 \mathrm{~h}$, the mixture was filtered, washed several times with CPME, and dried in vacuo. A sample was analyzed to determine the amount of palladium in the catalyst: $0.25 \%$.

The preparation of Cat $1^{*}$ was similar, but after the first phase, the solution was transferred, under an inert atmosphere, into a $50 \mathrm{~mL}$ double-neck jacket round-bottom flask that already contained alumina and CPME. The resulting mixture was finally stirred for $24 \mathrm{~h}$ at $25^{\circ} \mathrm{C}$ under hydrogen atmosphere and then worked as above.

\subsection{Preparation of Cat 2}

In a Schlenk tube, $7.5 \mathrm{mg}(0.0423 \mathrm{mmol})$ of $\mathrm{PdCl}_{2}, 16.4 \mathrm{mg}(0.1652 \mathrm{mmol})$ of $\mathrm{CuCl}$ $0.22 \mathrm{~mL}(0.50 \mathrm{mmol})$ of TOA, and $5 \mathrm{~g}$ of $\gamma-\mathrm{Al}_{2} \mathrm{O}_{3}$ were stirred under nitrogen in $10 \mathrm{~mL}$ of CPME. The Schlenk tube was transferred into a $150 \mathrm{~mL}$ stainless steel autoclave, pressurized with $2.5 \mathrm{MPa}$ of $\mathrm{H}_{2}$, and stirred for $24 \mathrm{~h}$ at $100{ }^{\circ} \mathrm{C}$. Then, the residual gas was released and the reaction mixture was filtered, washed several times with CPME, and dried in vacuo. A sample was analyzed to determine the amount of palladium and copper in the catalyst: $0.075 \%(\mathrm{Pd})$ and $0.156 \%(\mathrm{Cu})$.

\subsection{Hydrogenation of 3-hexyn-1-ol (I)}

All the hydrogenation reactions were carried out following a procedure similar to the procedure described below for the hydrogenation of I catalyzed by Cat 1 in i-propanol. Experimental details (different solvents, catalysts, substrate to metal molar ratios, reaction temperatures and times) are reported in Tables $\mathrm{S} 1-\mathrm{S} 6$.

A total of $100 \mathrm{mg}$ of Cat $1\left(0.25 \% \mathrm{Pd} / \mathrm{Al}_{2} \mathrm{O}_{3}\right)$ and $10 \mathrm{~mL}$ of i-propanol were introduced under nitrogen in a three-necked round-bottom flask. Then, $138.4 \mathrm{mg}(1.41 \mathrm{mmol})$ of I was introduced in the flask via a syringe and the mixture, vigorously stirred by a magnetic 
stirrer, and maintained under $0.1 \mathrm{MPa}$ of hydrogen at $20^{\circ} \mathrm{C}$. Samples were analyzed at different times by GC and GC-MS to check the course of the reaction. The amounts of (Z)-(II) and (E)-(II) were determined by comparison with the corresponding standards.

\section{Conclusions}

This study showed a useful application of an easily prepared and smart heterogeneous catalyst containing very low amounts of catalytic metallic species: the selective semihydrogenation of an internal alkyne to a $(Z)$-alkene, which should find wide applicability. In particular, many factors that may affect the outcome of the reaction were investigated in the context of an important industrial case, the hydrogenation of 3-hexyn-1-ol to (Z)-3hexen-1-ol, a fragrance having a multi-ton market in the world. It was possible to obtain a good balance between reactivity and selectivity, with performance comparable or usually superior to those of known available catalysts.

Supplementary Materials: The following are available online at https://www.mdpi.com/2073 $-4344 / 11 / 1 / 14 / s 1$, Figure S1: title, Table S1: title, Video S1: title. Tables S1-S6; Figures S1-S3: SEM of Cat $10.25 \% \mathrm{Pd} / \mathrm{Al}_{2} \mathrm{O}_{3}$ (1000 magnifications), Figure S4: SEM of Cat $1^{*} 0.25 \% \mathrm{Pd} / \mathrm{Al}_{2} \mathrm{O}_{3}$ (100,000 magnification), and Figure S5: SEM of Cat ${ }^{*} 0.25 \% \mathrm{Pd} / \mathrm{Al}_{2} \mathrm{O}_{3}$ (250,000 magnification).

Author Contributions: Conceptualization, O.P.; methodology, O.P. and S.P.; supervision, S.P.; investigation and analyses, A.A. and N.P.; writing—original draft preparation, O.P. and S.P.; writing—review and editing, O.P. All authors have read and agreed to the published version of the manuscript.

Funding: This research received no external funding.

Conflicts of Interest: The authors declare no conflict of interest.

\section{References}

1. Blaser, H.U.; Malan, C.; Pugin, B.; Spindler, F.; Steiner, H.; Studer, M. Selective Hydrogenation for Fine Chemicals: Recent Trends and New Developments. Adv. Synth. Catal. 2003, 345, 103-151. [CrossRef]

2. Vilé, G.; Albani, D.; Almora-Barrios, N.; López, N.; Pérez-Ramírez, J. Advances in the Design of Nanostructured Catalysts for Selective Hydrogenation. Chem CatChem 2016, 8, 21-33. [CrossRef]

3. Zhang, L.; Zhou, M.; Wang, A.; Zhang, T. Selective Hydrogenation over Supported Metal Catalysts: From Nanoparticles to Single Atoms. Chem. Rev. 2020, 120, 683-733. [CrossRef] [PubMed]

4. Campanati, M.; Fornasari, G.; Vaccari, A. Fundamentals in the preparation of heterogeneous catalysts. Catal. Today 2003, 77, 299-314. [CrossRef]

5. Munnik, P.; de Jongh, P.E.; de Jong, K.P. Recent Developments in the Synthesis of Supported Catalysts. Chem. Rev. 2015, 115, 6687-6718. [CrossRef]

6. Lindlar, H. Ein neuer Katalysator für selektive Hydrierungen. Helv. Chim. Acta 1952, 35, 446-450. [CrossRef]

7. Molnár, Á.; Sárkány, A.; Varga, M. Hydrogenation of carbon-carbon multiple bonds: Chemo-, regio- and stereo-selectivity. J. Mol. Catal. 2001, 173, 185-221. [CrossRef]

8. Anderson, J.A.; Mellor, J.; Wells, R.P.K. Pd catalysed hexyne hydrogenation modified by Bi and by Pb. J. Catal. 2009, 261, 208-216. [CrossRef]

9. Maccarrone, M.J.; Lederhosa, C.R.; Torresa, G.; Betti, C.; Coloma-Pascual, F.; Quiroga, M.E.; Yori, J.C. Partial hydrogenation of 3-hexyne over low-loaded palladium mono and bimetallic catalysts. Appl. Catal. A Gen. 2012, 441-442, 90-98. [CrossRef]

10. Crespo-Quesada, M.; Cárdenas-Lizana, F.; Dessimoz, A.-L.; Kiwi-Minsker, L. Modern Trends in Catalyst and Process Design for Alkyne Hydrogenations. ACS Catal. 2012, 2, 1773-1786. [CrossRef]

11. Witte, P.T.; Boland, S.; Kirby, F.; van Maanen, R.; Bleeker, B.F.; de Winter, D.A.M.; Post, J.A.; Geus, J.W.; Berben, P.H. NanoSelect Pd Catalysts: What Causes the High Selectivity of These Supported Colloidal Catalysts in Alkyne Semi-Hydrogenation? Chem CatChem 2013, 5, 582-587. [CrossRef]

12. Mitsudome, T.; Takahashi, Y.; Ichikawa, S.; Mizugaki, T.; Jitsukawa, K.; Kaneda, K. Metal-Ligand Core-Shell Nanocomposite Catalysts for the Selective Semihydrogenation of Alkynes. Angew. Chem. Int. Ed. 2013, 52, 1481-1485. [CrossRef] [PubMed]

13. Yarulin, A.; Yuranov, I.; Cárdenas-Lizana, F.; Alexander, D.T.L.; Kiwi-Minsker, L. How to increase the selectivity of Pd-based catalyst in alkynol hydrogenation: Effect of second metal. Appl. Catal. A Gen. 2014, 478, 186-193. [CrossRef]

14. Vilé, G.; Almira-Barrios, N.; Mitchell, S.; López, N.; Pérez-Ramírez, J. From the Lindlar Catalyst to Supported Ligand-Modified Palladium Nanoparticles: Selectivity Patterns and Accessibility Constraints in the Continuous-Flow Three-Phase Hydrogenation of Acetylenic Compounds. Chem. Eur. J. 2014, 20, 5926-5937. [CrossRef] [PubMed]

15. Fedorov, A.; Liu, H.J.; Lo, H.K.; Copéret, C. Silica-Supported Cu Nanoparticle Catalysts for Alkyne Semihydrogenation: Effect of Ligands on Rates and Selectivity. J. Am. Chem. Soc. 2016, 138, 16502-16507. [CrossRef] 
16. Lu, Y.; Feng, X.; Takale, B.S.; Yamamoto, Y.; Zhang, W.; Bao, M. Highly Selective Semihydrogenation of Alkynes to Alkenes by Using an Unsupported Nanoporous Palladium Catalyst: No Leaching of Palladium into the Reaction Mixture. ACS Catal. 2017, 7, 8296-8303. [CrossRef]

17. Delgado, J.A.; Benkirane, O.; Claver, C.; Curulla-Ferréc, D.; Godard, C. Advances in the preparation of highly selective nanocatalysts for the semi-hydrogenation of alkynes using colloidal approaches. Dalton Trans. 2017, 46, 12381-12403. [CrossRef]

18. Ibhadon, A.O.; Kansal, S.K. The Reduction of Alkynes Over Pd-Based Catalyst Materials-A Pathway to Chemical Synthesis. J. Chem. Eng. Process Technol. 2018, 9. [CrossRef]

19. Maazaoui, R.; Abderrahim, R.; ChemLa, F.; Ferreira, F.; Perez-Luna, A.; Jackowski, O. Catalytic Chemoselective and Stereoselective Semihydrogenation of Alkynes to E-Alkenes Using the Combination of Pd Catalyst and ZnI2. Org. Lett. 2018, 20, 7544-7549. [CrossRef]

20. Markov, P.V.; Bragina, G.O.; Baeva, G.N.; Rassolov, A.V.; Mashkovsky, I.S.; Stakheev, A.Y. Highly Selective Pd-Cu/ $\alpha$-Al2O3 Catalysts for Liquid-Phase Hydrogenation: The Influence of the Pd: Cu Ratio on the Structure and Catalytic Characteristics. Kinet. Catal. 2018, 59, 601-609. [CrossRef]

21. Da Silva, F.P.; Fiorio, J.L.; Gonçalves, R.V.; Teixeira-Neto, E.; Rossi, L.M. Synergic Effect of Copper and Palladium for Selective Hydrogenation of Alkynes. Ind. Eng. Chem. 2018, 57, 16209-16216. [CrossRef]

22. Swamy, K.K.C.; Reddy, A.S.; Sandeep, K.; Kalyani, A. Advances in chemoselective and/or stereoselective semihydrogenation of alkynes. Tetrahedron Lett. 2018, 59, 419-429. [CrossRef]

23. Buxaderas, E.; Volpe, M.A.; Radivoy, G. Selective Semi-Hydrogenation of Terminal Alkynes Promoted by Bimetallic Cu-Pd Nanoparticles. Synthesis 2019, 51, 1466-1472. [CrossRef]

24. Wei, Z.; Yao, Z.; Zhou, Q.; Zhuang, G.; Zhong, X.; Deng, S.; Li, X.; Wang, J. Optimizing Alkyne Hydrogenation Performance of Pd on Carbon in Situ Decorated with Oxygen-Deficient $\mathrm{TiO}_{2}$ by Integrating the Reaction and Diffusion. ACS Catal. 2019, 9 , 10656-10667. [CrossRef]

25. Guan, Q.; Zhang, J.; He, L.; Miao, R.; Shi, Y.; Ning, P. Selective Hydrogenation of Acetylene to Ethylene over the Surface of Sub-2 nm Pd Nanoparticles in Miscanthus sinensis-Derived Microporous Carbon Tubes. ACS Sustain. Chem. Eng. 2020, 8, 11638-11648. [CrossRef]

26. Spee, M.P.R.; Boersma, J.; Meijer, M.D.; Slagt, M.Q.; van Koten, G.; Geus, J.W. Selective Liquid-Phase Semihydrogenation of Functionalized Acetylenes and Propargylic Alcohols with Silica-Supported Bimetallic Palladium-Copper Catalysts. J. Org. Chem. 2001, 66, 1647-1656. [CrossRef]

27. Stoll, M.; Rouvé, A. Synthèse du cis- $\beta, \gamma$-hexénol (hexénol naturel). Helv. Chim. Acta 1938, 21, 1542-1547. [CrossRef]

28. Witte, P.T.; de Groen, M.; de Rooij, R.M.; Bakermans, P.; Donkervoort, H.G.; Berben, P.H.; Geus, J.W. Highly active and selective precious metal catalysts by use of the reduction-deposition method. Stud. Surf. Sci. Catal. 2010, 175, 135-143. [CrossRef]

29. Liguori, F.; Barbaro, P. Green semi-hydrogenation of alkynes by Pd@borate monolith catalysts under continuous flow. J. Catal. 2014, 311, 212-220. [CrossRef]

30. Steinhaus, M.; Sinuco, D.; Polster, J.; Osorio, C.; Schieberle, P. Characterization of the Key Aroma Compounds in Pink Guava (Psidium guajava L.) by Means of Aroma Re-engineering Experiments and Omission Tests. J. Agric. Food Chem. 2009, 57, 2882-2888. [CrossRef]

31. (Z)-hex-3-en-1-ol. Available online: http:/ / www.thegoodscentscompany.com/data/rw1005932.html (accessed on 22 December 2020).

32. Tassini, R.; La Sorella, G.; Montin, D.; Paganelli, S.; Baldi, F.; Piccolo, O. Sintesi sostenibili con CO. La Chimica e l'Industria 2012, $94,157$.

33. Paganelli, S.; Tassini, R.; Rathod, V.D.; Onida, B.; Fiorilli, S.; Piccolo, O. A Low Rhodium Content Smart Catalyst for Hydrogenation and Hydroformylation Reactions. Catal. Lett. 2020. [CrossRef]

34. Piccolo, O.; Verrazzani, A. US 7087548, (Chemi SpA). 2006. Available online: https://worldwide.espacenet.com/publicationDetails/ originalDocument?FT $=$ D\&date $=20060808 \& D B=E P O D O C \& l o c a l e=e n \_E P \& C C=U S \& N R=7087548 B 2 \& K C=B 2 \& N D=4($ accessed on 22 December 2020). 